\title{
Impact of Innovations Attributes on e-learning Acceptance among Sri Lankan Postgraduate Students
}

\author{
M R K N YATIGAMMANA \\ $\mathrm{Ph}$. D Candidate, Management \& Science University, Malaysia \\ Department of Commerce \& Financial Management, University of Kelaniya, Sri Lanka \\ kaushimail@yahoo.com \\ PROF.DR.MD GAPAR MD JOHAR \\ Management \& Science University \\ University Drive, Off Persiaran Olahraga, Malaysia \\ gapar@msu.edu.my \\ PROF.CHANDRA GUNAWARDHANA \\ COL-UNESCO Chair in Distance Education \\ Open University of Sri Lanka, Nugegoda, Sri Lanka \\ ggunawardena@hotmail.com
}

\begin{abstract}
Though e learning is gaining much popularity in Sri Lanka, the actual and potential users of elearning facilities possess different perceptions towards the acceptance of e-learning technology. As e learning is considered to be an innovative method for the users, the Diffusion of Innovation theory identifies five attributes of innovation namely relative advantage, compatibility, complexity, trialability, observability which impact on the attitude and intention of using $e$ learning by the users. Therefore examining the impact of innovation attributes on e learning acceptance in Sri Lankan postgraduates is more relevant as it helps to acquire the knowledge on how e learning acceptance is perceived by them. For this purpose random samples of 200 were drawn from the postgraduate students in local based universities in Sri Lanka and it was found that observability and relative advantage has a significant impact on attitude and intention of using e learning among the postgraduate students while least significant innovation attributes were found to be complexity and trialability.
\end{abstract}

Key words: e-learning, postgraduate, Sri Lanka. 


\section{Introduction}

The teaching and learning activities have been developed parallel to the technological developments. In this era of digital age, electronic media are mainly used to disseminate knowledge. The Ministry of Education in New Zealand defines e-learning as "learning that is enabled or supported by the use of digital tools and content. It typically involves some form of interactivity, which may include online interaction between the learner and their teacher or peers. E-learning opportunities are usually accessed via the internet, though other technologies such as CD-ROM are also used in e-learning." E-learning facilities can be seen in either synchronous or asynchronous form. Asynchronous e-learning is where the teaching and learning takes place even when the participants cannot be online. Though the users can still access to information and content and download them send feedbacks to the instructors via email, discussion boards, blogs, discussion forums etc. In contrast to this, synchronous learning is real time interaction between the learner and the instructor through videoconferencing, teleconferencing chat, instant messaging, etc. (Hrastinski, 2008; Koller, Harvey, \& Magnotta, 2001). Therefore, e-learning is a very advantageous method of accessing geographically dispersed users easily with the use of technology.

The studies done in abroad was found that the online MBA courses are mainly attracted by the adults over 35 years of age, females, part time, married students (Cao, 2010). Engelbrecht (2003) found that the students enrolled for e-learning Master's programme in Taxation of the University of South Africa are full-time employees and many of them are in the process of building a career and family and students indicated work pressure and family commitment as reasons for not completing the studies. The situation of Sri Lanka is also similar as majority of postgraduate students are engaged in learning while they are working and thus physically appearing in a class room is rather difficult for them.

In view of the fact that the postgraduate studies are mainly followed by the individuals who are working fulltime, geographically dispersed than undergraduates and with other obligations to fulfill such as commitment to families and social lives, there is a requirement for more flexible postgraduate courses offering with the help of the technology to address the needs of that particular clientele which allow them to obtain necessary qualifications overcoming the barriers. 
It is also found that higher educational institutions have also benefited from virtual classrooms as their cost can be reduced.

Rogers Diffusion of Innovation theory (DOI) has been used in many fields such as agriculture, medicine and ICT to measure the adoption of new innovations. Surry (1997) explained that using diffusion theories in educational technologies are important for the following reasons.

- To understand the factors that affect the adoption of innovation which either impedes or supports diffusion

- Since educational technology is an innovative method, by identifying diffusion theory the adopters can work more efficiently

- Both instructional technology and diffusion of innovation models have a systematic process of designing diffusion of model that can be used to design the instructional technology.

Therefore, ICT adoption in the education field can be measured using DOI theory as it is a new innovation in the field of education (Goktalay \& Ocak, 2006; Li, 2004; Perkins, 2011; Surry, 1997; Usluel, Aşkar, \& Baş, 2008).

The studies done in overseas on the area of e-learning, has depicted that it could gain more advantages and developments from users, institutional and social perspectives. As Sri Lanka is moving towards the concept of 'revival of Asia', the knowledge enrichment together with the technological advancement would truly lead the way to achieve the said concept. Therefore, to examine how innovation attributes of e-learning impact on attitude and intention towards using e-learning would be greatly beneficial for both existing and potential postgraduate students, instructors and educational institutions of Sri Lanka which have the desire for e-learning to understand the tangible situation of e-learning phenomenon and be able to make decisions accordingly. 


\section{Objectives}

The objectives of this study are to:

- examine the impact of innovations attributes on attitude of using e learning among Sri Lankan postgraduate students

- examine the impact of innovations attributes on intention of using e learning among Sri Lankan postgraduate students

\section{Literature Review}

According to Rogers (2003) the innovation decision process contain five stages namely, knowledge, persuasion, decision, implementation and confirmation. In the knowledge stage person searches for information on innovation based on what, how and why terms. Probably an individual attempts to ask what the innovation is and how and why it works. Rogers describes it as awareness knowledge, how to knowledge and principles knowledge.

In the second stage of innovation process, i.e. in the persuasion stage an individual may build either a negative or a positive attitude towards the innovation. Since Rogers describes the innovation diffusion process as "an uncertainty reduction process" the process attributes that are discussed under the persuasion stage help to decrease the uncertainty on innovation. The attributes that are discussed in this stage are relative advantage, compatibility, complexity, trialability and observability.

\section{Relative Advantage}

Rogers explains relative advantage as the "degree to which an innovation is perceived better than the ideas it supersedes" (p.229). Relative advantage is measured in terms of economics, social prestige, convenience and satisfaction. Also motivational aspects, demand, value are the most hunted advantages that an individual seeks. Even if the equipment and facilities are available for the faculty if the faculty does not see the benefit of them they would not use them. Further if administration does not motivate and value the new work that the faculty is going to undertake it will also lead to reduce the relative advantage as perceived by the individuals (McKenzie, 2001; Spotts, 1999). 


\section{Compatibility}

Compatibility is the "degree to which an innovation is perceived as consistent with the existing values, past experiences, and needs of potential adopters." (p.240). The compatibility dimensions include to what extent an innovation fits the values, beliefs, previous ideas and needs of the users (Perkins, 2011). Individual's negative attitude towards IT may be affected by the lack of compatibility (McKenzie, 2001).

\section{Complexity}

Complexity is "the degree to which an innovation is perceived as relatively difficult to understand and use" (p.257). If the complexity of the innovation increases the adoption is decreased. If the system is user friendly and the users have a prior training on the use of computer equipment, support systems and technical knowledge then the adoptability increases (Martin, 2003). In instructional technology, complexity depends on the producers' capability of designing the materials and how the content adheres to the best practices (Perkins, 2011).

\section{Trialability}

As Rogers defines, trialability is 'the degree to which as innovation may be experimented with on a limited basis' (p.258). More the innovation is tried the faster the adoption is. If an institution publishes its materials to the world at large and if it is to be useful, allowing a trial basis for the users would be effective and also problems can be solved before they get worsen (Perkins, 2011)

\section{Observability}

According to Rogers, observability is "the degree to which the results of an innovation are visible to others" (p.258). If the results are visibly observable by people then the adoption is increased.

According to the above model of Rogers' DOI, persuasion stage of the innovation decision process explains the individuals' adoption for the acceptance of the innovation. Therefore, the innovation attributes that are discussed in the persuasion stage are mainly beneficial to ascertain the attitude of e-learning adoption of the students. 
Rogers' diffusion of innovation has been tested by many studies on users' technological adoption and various conclusions have been made in different contexts.

According to Liao \& Lu (2008) perceived compatibility positively influences the students' intention to use e-learning and trialability is negatively related with e-learning adoption. Further it was found that perceived e-learning advantage; complexity and observability have no significant effect on students' intent of adoption of e-learning. As per Duan, et al.,(2010) only the perceived compatibility and trialability have a significant influence on e-learning adoption among the Chinese undergraduates. Another Chinese study done on e-learning adoption of undergraduates, found the most influential factors for e-learning adoption are pricing under relative advantage, education quality under compatibility, IT equipment under complexity and flexibility under relative advantage (Zhang, Wen, Li, Fu, \& Cui, 2010). Fu et al., (2010) found perceived e-learning relative advantage, compatibility, trialability and observability have a significant positive influence on students' e-learning adoption and that perceived level of complexity has no significant effect on students' e-learning acceptance. Similar findings were derived by Al-Gahatni (2003) where relative advantage, compatibility, trialability and observability shows a positive significant correlation with computer technology adoption in Saudi Arabian knowledge workers and complexity shows a negative relation with computer adoption.

The researchers also have attempted to find out the impact between innovation attributes and attitudes of using technologies, because attributes of innovation would have been an effect on changing the attitude of a person before altering the behavioral intention of the users. Therefore Folorunso (2010) concluded that relative advantage and complexity did not show a significant impact on attitude but compatibility, observability and trialability have a positive significant impact on attitude of using social network sites of the student in Nigerian universities. They further elaborated that though students see speed, availability, ease of use in other social network sites even though they do not like to switch from one network to the other network. Therefore relative advantage does not provide any significant effect on attitude. It was also found that social network sites are not easy to use and not widely spread. Therefore contribution of complexity is also found to be insignificant. The observability of the technology was affected from the others perception and influence. The trialability shows a higher significance towards the 
attitude of using technology, because students have already tested the trialability of the site and perceived it as high. It is also found that innovation attributes are significant determinants of internet banking attitude of the users (Zolait, 2009).

According to the literature on past studies done on DOI theory and e-learning acceptance, seven main variables can be identified. i.e. relative advantage, compatibility, complexity, trialability and observability as innovation attributes and attitude and intention of using e-learning as elearning acceptance factors.

\section{The Conceptual Framework}

The following conceptual framework is derived based on the literature survey.

\begin{tabular}{|c|c|}
\hline $\begin{array}{c}\text { Relative advantage (perceived } \\
\text { usefulness) }\end{array}$ & $\begin{array}{l}\text { Attitude } \\
\text { towards using }\end{array}$ \\
\hline $\begin{array}{c}\text { Complexity (perceived ease } \\
\text { of use) }\end{array}$ & e-learnir \\
\hline Trialability & Behavioral \\
\hline Compatibility & e-learning \\
\hline Observability & \\
\hline
\end{tabular}

\section{Figure01: Conceptual Framework}

\section{Research Methodology}

The G Power software was used to determine the sample size for the study(Cunningham JB \& McCrum-Gardner E, 2007; Faul Franz, lder Edgar Erdfe, Buchner Axel, \& Lang, 2009). Accordingly the sample was 187. Therefore 200 questionnaires were distributed among the postgraduate students who are registered in the universities for year 2010/2011 and 2011/2012. The sample was randomly drawn from the locally based universities in Sri Lanka. Duly filled 191 questionnaires were taken for the analysis.

The reliability of the variables is tested using Cronbach' alpha and all the variables are shown a good level of reliability as in table 1. 
Table 01: Reliability test of the variables

\begin{tabular}{|l|l|}
\hline Variable & Cronbach's Alpha \\
\hline Relative advantage & .845 \\
\hline Compatibility & .735 \\
\hline Complexity & .885 \\
\hline Trialability & .873 \\
\hline Observability & .811 \\
\hline Attitude & .906 \\
\hline Intention & .852 \\
\hline
\end{tabular}

\section{Results and Discussion}

The table 2 shows the background information of the respondents.

Table 02: Background information of the respondents

\begin{tabular}{|l|l|}
\hline Age & $\%$ \\
\hline $12-18 \mathrm{yrs}$ & 1.0 \\
\hline $19-30 \mathrm{yrs}$ & 71.2 \\
\hline $31-40 \mathrm{yrs}$ & 21.5 \\
\hline $41-55 \mathrm{yrs}$ & 5.8 \\
\hline $56-65 \mathrm{yrs}$ & 0.5 \\
\hline
\end{tabular}




\begin{tabular}{|c|c|}
\hline Gender & \\
\hline Male & 60.2 \\
\hline Female & 39.8 \\
\hline \multicolumn{2}{|l|}{ Marital status } \\
\hline Single & 68.1 \\
\hline Married & 31.9 \\
\hline \multicolumn{2}{|c|}{ Current programme of study } \\
\hline Management & 13.6 \\
\hline Arts & 26.7 \\
\hline Engineering & 10.5 \\
\hline Medicine & 1.0 \\
\hline Education & 7.9 \\
\hline Science & 13.1 \\
\hline IT & 18.8 \\
\hline Other & 8.4 \\
\hline \multicolumn{2}{|c|}{ Highest education completed } \\
\hline professional exams & 2.6 \\
\hline Diploma & 2.6 \\
\hline First degree & 77.5 \\
\hline PG degree & 16.2 \\
\hline $\mathrm{PhD}$ & 1.0 \\
\hline
\end{tabular}




\begin{tabular}{|l|l|}
\hline Current employment & \\
\hline Education & 39.8 \\
\hline Managerial & 12.0 \\
\hline Medical & 1.6 \\
\hline Engineering & 11.5 \\
\hline IT related & 15.7 \\
\hline Other & 17.8 \\
\hline Without job & 1.6 \\
\hline
\end{tabular}

Source: Author

According to the table 2, the majority of the respondents are from the age group between 19 to 40 years. Majority of the respondents are males and singles. Most of the respondents are following arts programmes and have a first degree as the highest educational qualification. Majority of the respondents are working in the education field.

- Objective 1: Examine the impact of innovations attributes on attitude among Sri Lankan postgraduate students

Table 03: Model Summary

\begin{tabular}{|l|l|l|l|}
\hline & R Square & F & Sig. \\
\hline Sri Lanka & .422 & 27.063 & 0.000 \\
\hline
\end{tabular}

Source: Author

The R-squared of 0.422 implies that the five predictor variables explain about $42.2 \%$ of the variance/variation in the attitude. The ANOVA revealed that the F-statistics $(F=27.063)$ is very large and the corresponding p-value is highly significant (0.000) or lower than the alpha value of 0.05. This indicates that the slope of the estimated linear regression model line is not equal to 
zero confirming that there is a linear relationship between attitude of using e learning and the five predictor variables.

Table 04: Regression analysis for the dependent variable attitude

\begin{tabular}{|l|l|l|l|l|l|l|}
\hline Country & Dimensions & $\begin{array}{l}\text { B(Unstandardized } \\
\text { Coefficients })\end{array}$ & $\begin{array}{l}\text { Std. } \\
\text { Error }\end{array}$ & $\begin{array}{l}\text { Beta(Standardized } \\
\text { Coefficients })\end{array}$ & $\mathrm{t}$ & $\mathrm{p}$-value \\
\hline Sri Lanka & (Constant) & 3.105 & 1.277 & & 2.432 & .016 \\
\hline & Relative & .161 & .043 & .303 & 3.740 & .000 \\
\hline & Compatibility & .078 & .047 & .144 & 1.666 & .097 \\
\hline & complexity & -.032 & .034 & -.057 & -.942 & .347 \\
\hline & trialability & .084 & .065 & .102 & 1.290 & .199 \\
\hline & observability & .267 & .101 & .226 & 2.643 & .009 \\
\hline
\end{tabular}

$P$ value-0.05 level

\section{Source: Author}

As depicted in table 4, the largest beta coefficient is for observability. This means that this variable makes the strongest unique contribution to explaining the dependent variable (attitude) when the variance explained by all other predictor variables in the model is controlled for. It suggests that increase of one standard deviation in observability is followed by 0.267 standard deviation increases the attitude of using e learning mode among Sri Lankan postgraduate students. The Beta value for relative advantage is the second highest (0.161). The third highest Beta value is for trialability (0.084). The beta value for compatibility is the fourth highest $(0.078)$ while complexity records the smallest (-0.032) which indicates that it made the least contribution. The negative symbol indicates negative linear relationship between the predictor and the dependent variable. It means that one standard deviation increase in complexity of the users is followed by 0.032 standard deviation decrease in attitude towards using e learning. Based on the collinearity diagnostic table obtained, none of the model dimensions has condition index above the threshold value of 30.0 , none of tolerance value smaller than 0.10 and VIF 
statistics are less than 10.0. This indicated that there is no serious multicollinearity problem among the predictor variables of the model.

- Objective 2: Examine the impact of innovations attributes on intention among Sri Lankan postgraduate students

Table 05: Model Summary

\begin{tabular}{|l|l|l|l|}
\hline & R Square & F & Sig. \\
\hline Sri Lanka & .390 & 23.618 & 0.000 \\
\hline
\end{tabular}

Source: Author

The R-squared of 0.390 implies that the five predictor variables explain about $39 \%$ of the variance/variation in the intention. The ANOVA revealed that the F-statistics $(F=23.618)$ is very large and the corresponding p-value is highly significant (0.000) or lower than the alpha value of 0.05 This indicates that the slope of the estimated linear regression model line is not equal to zero confirming that there is linear relationship between attitude of using e learning and the five predictor variables.

Table 06: Regression analysis for the variable intention

\begin{tabular}{|l|l|l|l|l|l|l|}
\hline Country & Dimensions & $\begin{array}{l}\text { B(Unstandardized } \\
\text { Coefficients) }\end{array}$ & $\begin{array}{l}\text { Std. } \\
\text { Error }\end{array}$ & $\begin{array}{l}\text { Beta(Standardized } \\
\text { Coefficients) }\end{array}$ & $\mathbf{t}$ & $\begin{array}{l}\text { p- } \\
\text { value }\end{array}$ \\
\hline Sri Lanka & (Constant) & 6.416 & 1.355 & & 4.733 & .000 \\
\hline & Relative & .135 & .046 & .246 & 2.954 & .000 \\
\hline & Compatibility & .077 & .049 & .138 & 1.553 & .122 \\
\hline & complexity & -.011 & .036 & -.018 & -.292 & .770 \\
\hline & trialability & .019 & .069 & .022 & .274 & .784 \\
\hline & observability & .393 & .107 & .322 & 3.666 & .000 \\
\hline
\end{tabular}

Source: Author

$p=0.05$ 
As depicted in Table 7, the largest beta is for observability which is 0.393 . This means that this variable makes the strongest unique contribution to explaining the dependent variable (intention) when the variance explained by all other predictor variables in the model is controlled for. It suggests that one standard deviation increase in observability is followed by 0.393 standard deviation increase in attitude. The Beta value for relative advantage is the second highest (0.135). The third highest Beta value is for compatibility (0.077). The beta value for trialability is the fourth highest (0.019) while the Beta value for complexity is the smallest (-0.011) indicating that it made the least contribution. The negative symbol indicates negative linear relationship between the predictor and the dependent variable. It means that one standard deviation increase in complexity in users is followed by 0.011 standard deviation decrease in intention towards using e learning.

Table 07: Collinearity diagnostics of the variables

\begin{tabular}{|l|l|l|l|l|l|}
\hline \multirow{2}{*}{ Dimension } & Eigenvalue & Condition & \multirow{2}{*}{ (Constant) } & \multicolumn{2}{|l|}{ Collinearity Statistics } \\
\cline { 4 - 7 } & & Index & & Tolerance & VIF \\
\hline 1 & 5.877 & 1.000 & .00 & & \\
\hline 2 & .069 & 9.225 & .00 & .477 & 2.096 \\
\hline 3 & .020 & 16.981 & .06 & .419 & 2.389 \\
\hline 4 & .018 & 18.198 & .42 & .860 & 1.163 \\
\hline 5 & .009 & 25.211 & .02 & .503 & 1.989 \\
\hline 6 & .007 & 29.440 & .49 & .427 & 2.339 \\
\hline
\end{tabular}

Source: Author

Since there is no multicollinearity problem between the predictors in the final model and the assumptions of normality, equality of variance and linearity are all met, it is reasonable to conclude that the estimated multiple regression models to explain attitude is stable, good and quite respectable. 


\section{Conclusions and Recommendations}

This study aimed to examine the impact of perceived innovation attributes on attitude and intention of using e learning technology among Sri Lankan postgraduate students. In the data analysis it was found that if postgraduate students are perceived that the benefits of the e learning can be visible (observability) and if e learning can gain advantages in terms of economics, social prestige, convenience and satisfaction (relative advantage) it would lead to increase the attitude and intention of using e learning in Sri Lanka. On the other hand if postgraduate students are perceived using e learning is difficult (complexity) it would decrease the attitude and intention of using e learning mode. Also the increment of perceived trialability leads to increase attitude and intention of using e learning. Further, if e learning is consistent with their existing values, experiences and the needs (compatibility), it increases the attitude and intention of using $\mathrm{e}$ learning.

It is recommended that Sri Lanka should focus more on reduction of the complexity of e learning tools and exploit more user friendly techniques as to reduce the student's perception on complexity. Sri Lanka should place further effort on developing an e learning environment which the benefits are apparent and can gain advantages in economic, social, convenient and satisfaction. Also e learning should be more consistent to the values, experiences and needs of the potential and existing postgraduate students in Sri Lanka as it leads to increase the attitude and intention of using e learning. Further, if higher educational institutions can put more effort on making the potential students aware of the advantages and communicate them the benefits of e learning, the acceptance would be increased.

According to students' perspective they should attempt to be familiar with the technology and request from the institutions to have a prior trail to reduce the perception of complexity and to increase the trialability. Being an adult learner with lots of other commitments in the life e learning would be the best solution for the postgraduate students. Therefore, they should be thorough with the consistency of e learning solution with their typical life style. 


\section{References}

Al-Gahtani, S. S. (2003). Computer technology adoption in Saudi Arabia: Correlates of perceived innovation attributes. Information Technology for Development 10, 57-69.

Cao, Y. (2010). The Two Worlds of Adult MBA Education: Online v. Traditional Courses in Student Background and Performance. Paper presented at the Adult Higher Education Alliance Conference The Future of Adult Higher Education: Principles, Contexts and Practices.

Cunningham JB, \& McCrum-Gardner E. (2007). Power, effect and sample size using GPower: practical issues for researchers and members of research ethics committees. Evidence Based Midwifery, 5(4), 132-136.

Duan, Y., He, Q., Feng, W., Li, D., \& Fu, Z. (2010). A study on e-learning take-up intention from an innovation adoption perspective: A case in China. Computers \& Education, 55, 237-246.

Engelbrecht, E. (2003). A look at e-learning models: investigating their value for developing an e-learning strategy. Progressio 25(2), 38-47.

Faul Franz, lder Edgar Erdfe, Buchner Axel, \& Lang, A. r.-G. (2009). Statistical power analyses using G*Power 3.1:Tests for correlation and regression analyses. Behavior Research Methods, 41(4), 1149-1160.

Folorunso, O., Vincent, R. O., Adekoya, A. F., \& Ogunde, A. O. (2010). Diffusion of Innovation in Social Networking Sites among University Students. International Journal of Computer Science and Security 4(3).

Fu, Z., Yue, J., Li, D., Zhang, X., Zhang, L., \& Gao, Y. (2010). Evaluation of learner adoption intention of e-learning in China: A methodology based on perceived innovative attributes. New Zealand Journal of Agricultural Research, 50(5), 609-615.

Goktalay, S. B., \& Ocak, M. A. (2006). Faculty Adoption of Onlline Technology in Higher Education The Turkish Online Journal of Educational Technology, 5(4), 37-43. 
Hrastinski, S. (2008). Asynchronous \& Synchronous e learning. Educasue quartley, 4.

Koller, V., Harvey, S., \& Magnotta, M. (2001). Technology-Based Learning Strategies

Li, Y. (2004). Faculty perceptions about atrributes and barriers impacting Diffusion of web based distance education (WBDE) at the China Agricultural University Texas A\&M University.

Liao, H. L., \& Lu, H. P. (2008). The role of experience and innovation characteristics in the adoption and continued use of e-learning websites. Computers and Education, 51(4), 14051416.

Martin, M. H. (2003). Factors influencing faculty adoption of web-based courses in teacher education programs within the State University of New York Blacksburg, Virginia.

McKenzie, J. (2001). How Teachers Learn Technology Best. The Educational Technology Journal, 10(6).

PANdora: Distance and Open Resource Access. (2009). Distance Education Technology in Asia

Perkins, R. A. (2011). Using Rogers' Theory of Perceived Attributes as a Framework for Understanding the Challenges of Adoption of Open Educational Resources. International Journal of Humanities and Social Science 1(18), 59-66.

Rogers, E. M. (2003). Diffusion of Innovations (Vol. 5th edition): Free Press.

Spotts, H. T. (1999). Discriminating factors in faculty use of instructional technoloy in higher education. Eductaional Technology \& Society, 2(4).

Surry, D. W. (1997). Diffusion Theoory and Instructional Technology. Paper presented at the Annual Conference of the Association for Educational Communications and Technology (AECT).

Usluel, Y. K., Aşkar, P., \& Baş, T. (2008). A Structural Equation Model for ICT Usage in Higher Education Educational Technology \& Society, 11(2), 262-273. 
Zhang, L., Wen, H., Li, D., Fu, Z., \& Cui, S. (2010). E-learning adoption intention and its key influence factors basedon innovation adoption theory. MathematicalandComputerModelling, 51, 1428-1432.

Zolait, A. H. S. (2009). UIBR - An Approach to Innovations Acceptance. Journal of Internet Banking and Commerce, 14(2). 